\title{
Usefulness of Vocal Fatigue Index for Hypertension of Extrinsic Laryngeal Muscles
}

\author{
Ji-Sung Kim¹ ${ }^{10}$ and Dong-Wook Lee ${ }^{2}$ (D) \\ 'Department of Otorhinolaryngology, Chungbuk National University Hospital, Cheongju, Korea \\ 2Department of Otorhinolaryngology-Head and Neck Surgery, Chungbuk National University College of Medicine, Cheongju, Korea
}

후두외근 과긴장에 대한 음성피로도 검사의 유용성

김지성 ${ }^{1}$, 이동욱 ${ }^{2}$

1충북대학교병원 이비인후과, ${ }^{2}$ 충북대학교 의과대학 두경부외과학교실

Background and Objectives This study compares Vocal Fatigue Index (VFI) scores according to the presence or absence of external laryngeal tension in hyperfunctional voice disorder. And through this, it is to confirm the usefulness of VFI to hypertension of extrinsic laryngeal muscles. Materials and Method The subjects were 61 female diagnosed with hyperfunctional voice disorder (hypertension group 41, non-hypertension group 20). The author palpated extrinsic laryngeal muscles for evaluation of hypertension and classified them as the presence or absence. The voice measurements were jitter, shimmer, Korean-Voice Handicap Index-10 (K-VHI-10), and Korean-Vocal Fatigue Index (K-VFI). The voice compared were according to the diagnosis and presence of hypertension only for patients with hyperfunctional voice disorder.

Results As a result of comparing the voice measurement according to the presence or absence of hypertension, there was no significant difference in the acoustic variables, $\mathrm{K}-\mathrm{VHI}-10$ and $\mathrm{K}$ VFI-Total, K-VFI-Fatigue. Whereas, K-VFI-Physical $(p=0.006)$ and K-VFI-Rest $(p=0.022)$ were significantly higher in the hypertension group.

Conclusion These results indicate that the hypertension group has more physical discomfort and less voice recovery than the group without hypertension. It means that K-VFI can measure the physical discomfort and limitations of voice recovery due to hypertension of the external laryngeal muscle. The VFI can be used as one of the methods to evaluate the hypertension of the external laryngeal muscle in Hyperfunctional voice disorder.

Keywords Evaluation of laryngeal hypertension; Vocal Fatigue Index; Laryngeal palpation.

\section{서 론}

후두외근은 후두내근에 비해 상대적으로 크기가 크며, 후두의 위치와 후두골격의 안 정화를 유지하여, 발성 시 후두내근이 다른 방해없이 자연스럽게 움직이도록 돕는다. 후두를 올리거나 내리는 후두외근의 운동은 후두연골 사이의 근육을 긴장시키거나 연 골 사이의 각을 변화시킴으로써 음성에 영향을 미친다[1]. 후두외근의 과긴장으로 인해 후두의 위치(vertical laryngeal position)가 상승되면 후두의 연골구조가 불안정해지며

\author{
Received July 20, 2021 \\ Revised August 6, 2021 \\ Accepted September 15, 2021

\section{Corresponding Author} \\ Dong-Wook Lee, MD \\ Department of Otorhinolaryngology- \\ Head and Neck Surgery, \\ Chungbuk National University \\ College of Medicine, \\ 776 1sunhwan-ro, \\ Cheongju 28644, Korea \\ Tel +82-43-269-6150 \\ Fax+82-43-269-6609 \\ E-mail dwlee@chungbuk.ac.kr
}

\section{ORCID iDs}

Ji-Sung Kim (D)

https://orcid.org/0000-0003-2363-5060

Dong-Wook Lee (D)

https://orcid.org/0000-0002-3333-6083

This is an Open Access article distributed under the terms of the Creative Commons Attribution Non-Commercial License (https://creativecommons.org/ licenses/by-nc/4.0) which permits unrestricted non-commercial use, distribution, and reproduction in any medium, provided the original work is properly cited. 
후두내근에 영향을 미쳐 성대의 긴장도가 변화되고 음성산출 이 방해를 받는다[2]. 특히, 갑상설골근의 과긴장은 후두의 수 직적 위치를 상승시키며, 이로 인해 성대 조직이 강성(stiffens) 해지고, 조이는 듯(tight)한 성대 내전 패턴이 형성된다[3].

기존에 보고된 후두 과긴장을 평가하는 방법에는 후두내 시경, 방사선촬영(radiography), 근전도검사(electromyography, EMG), 후두촉진검사 등이 있다. 후두내시경은 후두의 상승과 부적절한 성대진동 패턴을 야기하는 성문 전후의 압 축을 직접 관찰 할 수 있다는 장점이 있으나, 성문 전후의 압 축이 후두외근의 변화를 충분히 설명하지는 못한다는 한계점 이 있고, 구역반사(gag reflex)로 인해 나타나는 과긴장과의 감 별이 어렵다는 단점을 가진다[4]. 측두부 엑스선(lateral cephalogram)은 후두의 움직임을 평가할 수 있는 객관적인 방법 이지만, 음성클리닉에서 일상적으로 사용하는데 한계가 있을 뿐만 아니라, 과긴장으로 인한 설골의 상승이나 갑상연골과 설골 사이 수축 등과 같은 변화를 정상과 구별되는 특성으로 삼기에는 그 근거가 부족하다[5]. 근전도검사(EMG)는 후두신 경시스템과 근육을 평가하는 데 사용할 수 있는 표준화된 방 법이지만, 후두의 과긴장과 같은 신경학적 문제가 없는 경우 에 적용하기에는 그 근거가 충분치 않다[6]. 반면, $\mathrm{EMG}$ 중 피 부표면에 전극을 붙이는 surface electromyography (sEMG) 는 과기능적 음성장애와 정상 음성의 후두과긴장 차이를 객 관적으로 측정 할 수 있으며 후두촉진을 이용한 후두과긴장 평가와도 상관을 가진다[7]. 하지만, 일부 연구에는 $\mathrm{sEMG}$ 가 근육긴장성발성장애(muscle tension dysphonia, MTD)와 정 상 음성과의 차이를 감별하지 못하고 근육긴장성발성장애 환 자의 후두외근 과긴장 증가를 감지(detect) 못한다고 보고되 기도 하였다[8]. sEMG는 비침습적이고 객관적인 평가방법일 뿐만 아니라 음성치료 시 바이오 피드백으로 사용될 수 있다 는 장점이 있지만, 장비가 비싸며 이를 이용하고 해석하기 위 한 훈련이 필요해 임상에서의 효율성은 다소 떨어진다[4].

후두를 촉진하여 과긴장을 평가하는 후두촉진(laryngeal palpation)은 sEMG로 측정한 후두외근의 후두과긴장 평가 결과와 유의한 상관을 가지는 타당하고 신뢰 할 수 있는 비도 구적인 방법이다[7]. 발성 시나 휴식 동안 후두근육의 긴장과 통증, 높은 후두 위치, 설골-갑상연골 사이 공간감소, 후두 연골의 비정상적인 배치와 죄어짐(tightness), 유연성(tenderness), 후두의 측면 이동성(laryngeal lateral mobility) 등을 척도화하여 과긴장의 심한 정도를 평가한다[9]. 임상현장에 서 쉽고 빠르게 후두의 과긴장을 평가할 수 있는 장점이 있으 나, 정상 후두의 구조와 기능뿐만 아니라 병리적인 음성장애 에 대한 지식과 임상경험을 바탕으로 하는 주관적인 방법으 로서 임상숙련도에 따라 차이를 보일 수 있다[10].
설문지 형태의 주관적인 환자중심 음성평가는 다면적인 음 성평가 중 하나로 시행되고 있다. 최근에는 음성피로도 검사 (Vocal Fatigue Index, VFI)가 개발되었다. VFI는 음성사용 에 의해 발생하는 개인의 신체적 변화나 경험 등을 지칭하는 일련의 증상과 휴식으로 인해 이와 같은 증상의 호전을 지칭 하는 음성피로(vocal fatigue)를 평가한다[11]. 음성피로는 구 체적으로, 음성남용에 의해 발생하는 쉬거나 거친 음질, 말하 는 동안 호흡의 소진, 기식성 발성, 불완전한 음성, 음성 상실, 음도일탈, 편안한 음도를 유지하기 어려움, 감소된 음도와 강 도 범위, 소리 전달력의 감소, 기침이나 헛기침 필요의 증가, 노력성 발성 증가와 같은 음성의 변화나 특성뿐만 아니라 어 깨나 목의 긴장과 통증, 목의 조임과 협착, 삼킴 중 통증, 목의 피로감, 목의 뒷부분이나 가슴의 통증 등과 같은 발성기관의 부정적 변화를 의미한다[12]. VFI는 음성피로를 음성회피 및 피로, 음성사용 시 신체적 불편감, 휴식 후 음성향상 등 3 가 지 영역으로 나누어 평가하며, 이 중 음성사용 시 신체적 불편 감은 신체적 측면으로 인한 음성에서의 불편함을 평가하는 음성장애지수(Voice Handicap Index, VHI)와 달리 직접적인 발성기관의 불편함이나 통증을 평가하기 때문에, 과기능적 음성장애의 발성기관 과긴장을 평가하는데 있어 유용하게 사 용 될 수 있다.

이에 본 연구는 과기능적 음성장애 환자를 대상으로 후두외 근의 과긴장 평가를 위한 VFI의 유용성을 알아보고자 하였다.

\section{대상 및 방법}

\section{연구 대상}

본 연구는 후향적 연구로 2018년 9월부터 2020년 8월까지 음성문제를 호소로 이비인후과를 내원한 환자 중 과기능적 음성장애(성대결절, 성대폴립, 근육긴장성발성장애)로 진단 받 은 환자를 대상으로 하였다. 인후두역류질환과 호흡기 질환, 난청과 신경학적 질환이 있거나 갑상선 등의 두경부 수술력이 나 후두외근에 영향을 줄 수 있는 성형수술 과거력이 있는 경 우, 갑상선 비대나 그 외 후두외근에 영향을 줄 수 있는 경우, 노화나 방사선 치료에 따른 후두경화가 나타나는 경우는 연 구대상자 제외조건으로 하여 이에 부합하는 61 명을 연구대상 자로 선정하였다(Table 1). 의무기록 중 음성평가의 후두외근 과긴장 평가결과와 음향학적 분석, 주관적인 음성장애 평가 결과를 이용하였다. 대상자는 모두 여성으로 근육긴장성발성 장애가 동반 여부에 따라 과긴장 그룹(41명)과 과긴장이 없는 그룹(20명)으로 구분하였다. 본 연구는 충북대학교병원 임상 시험심사위원회의 검토와 승인을 받아 진행되었다(No. CBNUH 2020-11-021-001). 
Table 1. Demographic information of patients

\begin{tabular}{lcc}
\multicolumn{1}{c}{ Diagnosis } & Number & Mean age (yr) \\
Hypertension group & 41 & 45.64 \\
Vocal fold nodule & 18 & \\
Vocal fold polyp & 11 & \\
Muscle tension dysphonia & 12 & \\
Non-hypertension group & 20 & 49.96 \\
Vocal fold nodule & 5 & \\
Vocal fold polyp & 10 & \\
Muscle tension dysphonia & 5 &
\end{tabular}

\section{후두외근 과긴장 평가}

연구자는 선행연구를 참고하여 후두외근을 크게 설골상근 (이복근, 경돌설골근, 하악설골근, 이설골근), 설골하근(갑상 설골근, 견갑설골근, 흉골설골근, 흉골갑상근), 흉쇄유돌근으 로 분류하고 엄지와 검지를 이용하여 후두촉진을 실시하였 다[13]. 후두외근의 과긴장 여부는 촉진 시 후두근육이 유연 함(tenderness) 없이 딱딱하게 수축(constriction)되었을 때 과긴장 여부를 있음으로 판단하였으며 촉진 시 환자의 통증 호소 유무를 참고하여 최종적으로 있음(presence)과 없음 (nothing)으로 평가하였다.

\section{음성측정}

대상자의 음성은 음향학적 분석과 주관적인 음성장애 평 가를 통해 측정되었다. 연구자는 음향학적 분석을 위해 소음 이 통제된 조용한 검사실에서 대상자의 /a/연장 발성을 $\mathrm{Com}^{-}$ puterized Speech Lab (CSL 4150B; KayPENTAX, Lincoln Park, NJ, USA)의 multi-dimensional voice program을 이 용하여 분석하였다. 대상자는 마이크와 입 사이 간격을 $10 \mathrm{~cm}$ 로 유지한 상태에서 /a/발성을 실시하였으며, 이 중 안정구간 1.5 초를 선택하여 주파수변동률(jitter percent)과 강도변동 률(shimmer percent)을 분석하였다. 환자가 느끼는 주관적인 음성 상태의 평가는 한국어판 음성장애지수-10 (Korean-Voce Handicap Index-10, K-VHI-10)과 한국어판 음성피로도 검사(Korean-Voice Fatigue Index, K-VFI)를 사용하였다 [14]. K-VFI는 총 19문항으로 영역 1은 음성회피 및 피로(11문 항), 영역 2 는 음성사용 시 신체적 불편감(5문항), 영역 3 은 휴 식 후 음성향상(3문항)으로 구성되어 있다(부록). 영역 3인 휴 식문항은 부정형 문장으로 구성된 영역 1과 2와는 다르게 긍 정형 문장으로 구성되어 있어 역채점 하였다.

\section{통계 분석}

통계분석은 SPSS (Statistics Package for the Social Science, version 21.0; IBM Corp., Armonk, NY, USA)를 이용
Table 2. Hypertension frequency comparison of extrinsic laryngeal muscles in normal and hypertension voice disorder group

$\begin{array}{cccr} & \begin{array}{c}\text { Nodules } \\ (\mathbf{n}=23)\end{array} & \begin{array}{c}\text { Polyp } \\ (\mathbf{n}=21)\end{array} & \begin{array}{r}\text { MTD } \\ (\mathbf{n}=17)\end{array} \\ \text { SHM } & & & \\ \text { P } & 4(17.4) & 0(0) & 3(17.6) \\ \text { N } & 19(82.6) & 21(100) & 14(82.4) \\ \text { IHM } & & & \\ \text { P } & 17(73.9) & 11(52.4) & 13(76.5) \\ \text { N } & 6(26.1) & 10(47.6) & 4(23.5) \\ \text { SCM } & & & \\ \text { P } & 10(43.5) & 6(28.6) & 11(64.7) \\ \text { N } & 13(56.5) & 15(71.4) & 6(35.3)\end{array}$

Data are presented as $\mathrm{n}(\%)$. MTD, muscle tension dysphonia; $\mathrm{P}$, presence; N, nothing; SHM, Suprahyoid muscle; IHM, Infrahyoid muscle; SCM, Sternocleidomastoid muscle

하였으며, 통계적 유의성은 모두 95\%수준에서 검증하였다. 성 대결절, 성대폴립, 근긴장성발성장애로 구성된 과기능적 발성 장애 집단을 대상으로 진단명에 따른 음성차이를 비교하기 위해 음향학적 분석(jitter, shimmer)과 주관적인 음성장애평 가(K-VHI-10, $\mathrm{K}-\mathrm{VFI})$ 의 결과를 one-way ANOVA로 분석 하였다. 후두과긴장 유무에 따른 음성차이는 독립검정 t-test 를 통해 분석하였다.

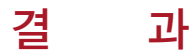

과기능적 발성장애군의 후두외근 과긴장 빈도

후두 촉진을 통해 후두외근 과긴장을 평가한 결과 설골상근 에서 $\mathrm{MTD}$ 의 과긴장 빈도는 $17.6 \%$, 성대결절이 $17.4 \%$ 이었으 며, 성대폴립은 과긴장이 없었다. 설골하근에서는 MTD 76.5\%, 성대결절 $73.9 \%$, 성대폴립 $52.4 \%$ 로 나타났다. 흥쇄유돌근에 도 MTD $64.7 \%$, 성대결절 $43.5 \%$, 성대폴립 $28.6 \%$ 의 빈도차 이가 나타났다. 과기능적 발성장애집단의 후두외근 별 과긴장 빈도는 설골하근(67.6\%), 흉쇄유돌근(45.6\%), 설골상근(11.7\%) 순이었으며, 집단 별로는 MTD (52.9\%), 성대결절(43.9\%), 성 대폴립(20.3\%)순으로 나타났다(Table 2).

\section{세부 진단명에 따른 음성 비교}

진단명에 따른 과기능적 발성장애 집단의 음성을 비교하였 다. 음향학적 변수인 jitter와 shimmer의 평균값은 성대결절에 서 각각 $2.27 \pm 1.77 \%, 11.40 \pm 5.19 \%$, 성대폴립이 $4.09 \pm 2.66 \%$, $12.30 \pm 4.70 \%$, 근육긴장성발성장애 $3.32 \pm 3.20 \% 10.63 \pm$ $6.22 \%$ 로 세 집단 간 유의한 차이가 없는 것으로 나타났다. 주 관적 음성장애 평가인 $\mathrm{K}-\mathrm{VHI}-10$ 과 $\mathrm{K}-\mathrm{VFI}$ 의 평균값은 성대 결절이 각각 $17.91 \pm 8.38$ 점과 $37.43 \pm 13.07$ 점이었고, 성대폴립 
Table 3. Comparison result of voice parameters and K-VHI-10, K-VFI in hypertensional voice disorder group

\begin{tabular}{|c|c|c|c|c|c|}
\hline & Nodules $(n=23)$ & Polyp (n=21) & MTD $(n=17)$ & $\mathrm{F}$ & p-value \\
\hline Jitter (\%) & $2.27 \pm 1.77$ & $4.09 \pm 2.66$ & $3.32 \pm 3.20$ & 2.842 & 0.066 \\
\hline Shimmer (\%) & $11.40 \pm 5.19$ & $12.30 \pm 4.70$ & $10.63 \pm 6.22$ & 0.463 & 0.632 \\
\hline K-VHI-10 & $17.91 \pm 8.38$ & $18.62 \pm 7.76$ & $19.82 \pm 10.07$ & 0.238 & 0.789 \\
\hline K-VFI-Total & $37.43 \pm 13.07$ & $37.71 \pm 18.03$ & $42.52 \pm 18.99$ & 0.547 & 0.581 \\
\hline K-VFI-Fatigue & $23.83 \pm 9.45$ & $23.95 \pm 12.07$ & $25.12 \pm 11.97$ & 0.076 & 0.894 \\
\hline K-VFI-Physical & $8.57 \pm 5.57$ & $8.67 \pm 5.99$ & $9.41 \pm 6.38$ & 0.112 & 0.432 \\
\hline K-VFI-Rest & $6.39 \pm 3.54$ & $5.10 \pm 3.62$ & $6.18 \pm 3.15$ & 0.852 & 0.432 \\
\hline
\end{tabular}

Data are presented as mean \pm standard deviation. K-VHI-10, Korean-Voice Handicap Index-10; K-VFI, Korean-Vocal Fatigue Index; K-VFIFatigue, related to tiredness of voice and voice avoidance; K-VFI-Physical, related to physical discomfort associated with voicing; K-VFI-Rest, related to improvement of symptoms with rest

Table 4. Comparison result of voice parameters and K-VHI-10, KVFI according presence of external laryngeal hypertension

$\begin{array}{lcccl} & \begin{array}{c}\text { Presence } \\ (\mathrm{n}=41)\end{array} & \begin{array}{c}\text { Nothing } \\ (\mathrm{n}=20)\end{array} & \mathrm{t} & \mathrm{p} \text {-value } \\ \text { Jitter (\%) } & 3.14 \pm 2.76 & 3.29 \pm 2.35 & -0.210 & 0.834 \\ \text { Shimmer (\%) } & 11.56 \pm 5.22 & 11.35 \pm 5.59 & 0.143 & 0.887 \\ \text { K-VHI-10 } & 19.21 \pm 8.89 & 17.53 \pm 7.90 & 0.710 & 0.481 \\ \text { K-VFI-Total } & 41.20 \pm 17.13 & 34.35 \pm 14.45 & 1.538 & 0.129 \\ \text { K-VFI-Fatigue } & 25.17 \pm 11.38 & 22.16 \pm 9.88 & 0.994 & 0.324 \\ \text { K-VFI-Physical } & 10.19 \pm 5.77 & 5.84 \pm 4.99 & 2.837 & 0.006^{* *} \\ \text { K-VFI-Rest } & 6.59 \pm 3.41 & 4.45 \pm 3.17 & 2.350 & 0.022^{*}\end{array}$

Data are presented as mean \pm standard deviation. ${ }^{*} \mathrm{p}<0.05 ;{ }^{* *} \mathrm{p}<0.01$. K-VHI-10, Korean-Voice Handicap Index-10; K-VFI, Korean-Vocal Fatigue Index; K-VFI-Fatigue, related to tiredness of voice and voice avoidance; K-VFI-Physical, related to physical discomfort associated with voicing; K-VFI-Rest, related to improvement of symptoms with rest

에서는 18.62 \pm 7.76 점, $37.71 \pm 18.03$ 점, 근육긴장성발성장애는 $19.82 \pm 10.07$ 점, 42.52 \pm 18.99 점으로 유의한 차이가 나타나지 않았다(Table 3).

\section{후두외근 과긴장 유무에 따른 음성 비교}

후두외근 과긴장 유무에 따른 음성을 비교한 결과, 음향학적 변수인 jitter와 shimmer의 평균값은 과긴장이 있는 집단은 각 각 $3.14 \pm 2.76 \%, 11.56 \pm 5.22 \%$, 과긴장이 없는 집단은 $3.29 \pm$ $2.35 \%, 11.35 \pm 5.59 \%$ 로 유의한 차이가 나타나지 않았다. 주관 적 음성장애 평가인 $\mathrm{K}-\mathrm{VHI}-10$ 과 $\mathrm{K}-\mathrm{VFI}$ 에서 과긴장이 있는 집단의 평균 점수는 각각 $19.21 \pm 8.89$ 점, $41.20 \pm 17.13$ 점 과긴

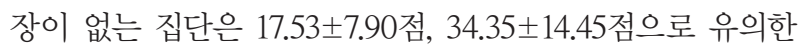
차이가 나타나지 않았다. 하지만, $\mathrm{K}-\mathrm{VFI}$ 중 음성사용과 관련 된 신체적 불편감을 나타나는 K-VFI-Physical에서 후두과 긴장이 있는 집단의 평균점수는 $10.19 \pm 5.77$ 점, 과긴장이 없

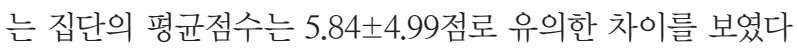
( $\mathrm{p}=0.006)$. 음성휴식 후 음성향상을 의미하는 K-VFI-Rest

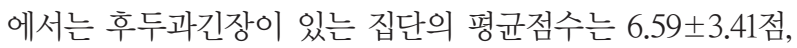

후두과긴장이 없는 집단은 4.45 \pm 3.17 점으로 유의한 차이가 나타났다 $(\mathrm{p}=0.022)$ (Table 4).

\section{고 찰}

정상 성대기능을 기준으로 발성 시 필요 이상의 과도한 기 능을 보이는 과기능적 음성장애(hyperfunctional voice disorder)의 발성기관은 성문상부의 수축과 과도한 성대내전, 높 은 후두 위치, 인두 협착과 같은 특징을 보인다[15]. 또한, 경돌 설골근(stylohyoid muscle)과 흉쇄유돌(sternocleidomastoid muscles), 갑상설골근(thyrohyoid muscle)의 수축(contraction)이나 단축(shortening)과 같은 후두외근의 비정상적 인 과긴장을 나타낸다[5]. 이와 같은 후두외근의 과긴장은 근 육긴장성발성장애뿐만 아니라, 발성 시 성대의 진동충격을 증가시켜 성대결절이나 폴립과 같은 성대점막의 병리학적 문 제로 이어질 수 있다[16]. 또한, 후두미세술을 통해 성대점막 의 종물 제거이후에도 과긴장으로 인한 발성문제는 지속될 수 있다[17]. 이처럼 후두외근의 과긴장이 과기능적 음성장애 의 병태생리와 치료 미치는 영향을 고려했을 때, 후두외근의 과긴장 평가는 과기능적 음성장애 치료의 중요한 요소 중 하 나라고 할 수 있다. 앞서 기술한 바와 같이 후두외근의 과긴 장을 평가하는 방법들은 각각의 장점과 한계점이 존재하기 때 문에 타당하고 신뢰 할 수 있는 평가를 위해서는 다면적 평가 가 시행되는 것이 바람직하다.

본 연구는 후두외근의 과긴장 평가에 있어 VFI의 유용성 을 알아보기 위해 과기능적 음성장애를 대상으로 후두외근의 과긴장 유무에 따른 음성차이를 비교하였다. 연구결과, 후두 외근의 과긴장이 있는 집단이 후두외근의 과긴장이 없는 집 단에 비해 K-VFI-Physical과 K-VFI-Rest의 점수가 더 높 았다. 이는 후두외근의 과긴장이 있는 집단이 신체적 불편감 이 더 크고, 음성회복은 적게 나타남을 의미한다. 이러한 결과 는, $\mathrm{K}-\mathrm{VFI}$ 가 후두의 과긴장으로 인한 발성기관의 직접적인 
신체적 불편함뿐만 아니라 음성회복의 한계를 측정할 수 있 으며, 후두외근의 과긴장 평가에 있어 다면적 검사 중 하나로 서 유용하게 사용될 수 있는 방법임을 시사한다. VFI는 최근 개발된 음성평가 설문지로 후두외근의 과긴장과의 연관성에 대한 직접적인 연구를 찾아보기 힘드나, 최근 연구에 의하면 직업적 음성사용자가 호소하는 주된 음성증상인 음성사용의 불편함(거친 음성, 쉰 목소리, 말할 때 힘이 듦)과 발성기관의 신체적 불편함(목에 힘이 들어감, 말할 때 목에 통증)이 VFI 와 유의한 상관을 가지는 것으로 보고되었다[18,19]. 이와 같 은 선행연구는 VFI가 음성오남용에 의한 과기능적 음성장애 의 후두외근의 과긴장을 측정할 수 있다는 본 연구와 일맥상 통하는 결과라고 할 수 있겠다. $\mathrm{VFI}$ 와 $\mathrm{VHI}$ 의 상관에 대한 선행연구에서 VFI 중 음성회피 및 피로영역과 신체적 불편감 영역은 $\mathrm{VHI}$ 의 신체, 기능, 정서영역과 유의한 상관을 가지는 반면 음성휴식 영역은 VHI와 상관이 없었다[20]. 이는 VFI 가 후두외근의 과긴장평가뿐만 아니라 직업적 음성사용자와 같이 반복적이고 지속적인 음성사용이 요구되는 과기능적 음성장애 환자의 음성평가에 있어 휴식에 따른 음성회복이 라는 새로운 측면의 음성을 평가할 수 있음을 의미한다.

본 연구는 과기능적 음성장애만을 연구대상으로 하였다. 추후연구에서는 과도한 보상발성 형성으로 인해 후두근육이 과긴장 될 수 있는 과소기능적 음성장애나, 신경학적 음성장 애를 대상으로 한 연구가 필요하겠다.

\section{결 론}

$\mathrm{VFI}$ 는 과기능적 음성장애에서 후두외근의 과긴장으로 인 한 발성기관의 신체적 불편함뿐만 아니라 음성회복의 한계 를 측정할 수 있어, 음성평가 시 후두외근의 과긴장 평가를 위한 방법 중 하나로서 유용하게 사용될 수 있다.

중심 단어: 후두과긴장 평가; 음성피로도검사; 후두촉진.

\section{Acknowledgments}

None

\section{Conflicts of Interest}

The authors have no financial conflicts of interest.

\section{Authors' Contribution}

Conceptualization: Ji-Sung Kim. Data curation: Ji-Sung Kim. Formal analysis: Ji-Sung Kim. Investigation: Ji-Sung Kim. Methodology: Ji-Sung Kim. Project administration: Dong-Wook Lee. Supervision: Dong-Wook Lee. Writing — original draft: Ji-Sung Kim. Writing_review \& editing: Ji-Sung Kim. Approval of final manuscript: all authors.

\section{REFERENCES}

1. Van Houtte E, Van Lierde K, Claeys S. Pathophysiology and treatment of muscle tension dysphonia: A review of the current knowledge. J Voice 2011;25(2):202-7.

2. Rubin JS, Lieberman J, Harris TM. Laryngeal manipulation. Otolaryngol Clin North Am 2000;33(5):1017-34.

3. Shipp T. Vertical laryngeal position: Research findings and application for singers. J Voice 1987;1(3):217-9.

4. Khoddami SM, Nakhostin Ansari N, Izadi F, Talebian Moghadam S. The assessment methods of laryngeal muscle activity in muscle tension dysphonia: A review. Sci World J 2013;2013:507397.

5. Lowell SY, Kelley RT, Colton RH, Smith PB, Portnoy JE. Position of the hyoid and larynx in people with muscle tension dysphonia. Laryngoscope 2012;122(2):370-7.

6. Stepp CE, Heaton JT, Braden MN, Jetté ME, Stadelman-Cohen TK, Hillman RE. Comparison of neck tension palpation rating systems with surface electromyographic and acoustic measures in vocal hyperfunction. J Voice 2011;25(1):67-75.

7. Redenbaugh MA, Reich AR. Surface EMG and related measures in normal and vocally hyperfunctional speakers. J Speech Hear Disord 1989;54(1):68-73.

8. Van Houtte E, Claeys S, D'haeseleer E, Wuyts F, Van Lierde K. An examination of surface EMG for the assessment of muscle tension dysphonia. J Voice 2013;27(2):177-86.

9. Khoddami SM, Ansari NN, Jalaie S. Review on laryngeal palpation methods in muscle tension dysphonia: Validity and reliability issues. J Voice 2015;29(4):459-68.

10. Angsuwarangsee T, Morrison M. Extrinsic laryngeal muscular tension in patients with voice disorders. J Voice 2002;16(3):333-43.

11. Nanjundeswaran C, Jacobson BH, Gartner-Schmidt J, Verdolini Abbott K. Vocal fatigue index (VFI): Development and validation. J Voice 2015;29(4):433-40.

12. Solomon NP. Vocal fatigue and its relation to vocal hyperfunction. Int J Speech Lang Pathol 2008;10(4):254-66.

13. Roy N. Assessment and treatment of musculoskeletal tension in hyperfunctional voice disorders. Int J Speech Lang Pathol 2008;10(4):195209.

14. Kim MJ. Relationship between vocal fatigue index and voice handicap index for professional voice users [dissertation]. Seoul: Ehwa Womans Univ.;2017.

15. Guzman M, Castro C, Testart A, Muñoz D, Gerhard J. Laryngeal and pharyngeal activity during semioccluded vocal tract postures in subjects diagnosed with hyperfunctional dysphonia. J Voice 2013;27(6): 709-16.

16. Welham NV, Maclagan MA. Vocal fatigue: Current knowledge and future directions. J Voice 2003;17(1):21-30.

17. Kim JS, Choi SH, Choi CH, Lee DW. Effect of voice therapy for persistent dysphonia following laryngeal microsurgery. Commun Sci Disord 2019;24(2):525-34.

18. Kim JS, Choi SH. Voice problems and self-care practice for vocal health: Current status of Korean speech-language pathologists. Commun Sci Disord 2018;23(2):414-24.

19. Kim JS, Choi SH. Vocal fatigue and voice-related quality of life in Korean speech-language pathologists. Commun Sci Disord 2018;23(4): 1078-90.

20. Afkhami M, Amiri-Shavaki Y, Qhelichi L, Kamali M, Ensafi Z, Azari $S$. Correlation between vocal fatigue index and voice handicap index scores in persons with laryngeal pathologies. Func Disabil J 2019;2(1): $119-24$. 


\section{부록}

\section{음성피로도 검사(Vocal Fatigue Index)}

아래 표에는 일반적으로 음성문제와 관련되는 몇 가지 증상들이 나열되어 있습니다.

해당 증상들을 얼마나 자주 경험하는 지 0점부터 4점까지 해당되는 점수에 표시해 주십시오.

$0=$ 전혀 아니다.

$1=$ 거의 아니다.

2=때때로 그렇다.

$3=$ 거의 그렇다.

4=항상 그렇다.

Part I: 음성회피 및 피로

1. 일정시간 동안 목소리를 쓰고 난 후에는 말하고 싶은 기분이 들지 않는다.

2. 말을 많이 하면 목소리에 피로감이 느껴진다.

3. 말을 할 때 점점 더 힘겨워지는 것이 느껴진다.

4. 목소리를 쓸수록 점점 더 쉰 소리가 난다.

5. 말 하는 것이 일처럼 느껴진다.

6. 나는 일정시간 동안 목소리를 쓰고 난 후에 말을 더 이상 하지 않는 경향이 있다.

7. 말을 많이 해야 하는 자리나 상황을 피한다.

8. 퇴근 후에 가족과 이야기하는 것이 힘겹게 느껴진다.

9. 일정시간 동안 목소리를 쓰고 난 후에는 목소리를 내기가 힘이 든다.

10. 멀리서도 들릴 만 한 목소리를 내는 것이 힘이 든다.

11 일정시간 동안 목소리를 쓰고 난 후에는 목소리가 약해졌다고 느낀다.

$\begin{array}{lllll}0 & 1 & 2 & 3 & 4 \\ 0 & 1 & 2 & 3 & 4 \\ 0 & 1 & 2 & 3 & 4 \\ 0 & 1 & 2 & 3 & 4 \\ 0 & 1 & 2 & 3 & 4 \\ 0 & 1 & 2 & 3 & 4 \\ 0 & 1 & 2 & 3 & 4 \\ 0 & 1 & 2 & 3 & 4 \\ 0 & 1 & 2 & 3 & 4 \\ 0 & 1 & 2 & 3 & 4 \\ 0 & 1 & 2 & 3 & 4\end{array}$

Part II: 신체적 불편감

12. 목소리를 사용한 날이면, 하루가 끝날 때쯤에 목 전체에 통증을 느낀다.

13. 목소리를 사용한 날이면, 하루가 끝날 때쯤에 목 안쪽에 통증을 느낀다.

14. 말을 많이 하면 목이 부은 느낌이 든다.

15. 목소리를 사용할 때 목 안쪽이 아프다.

16. 목소리를 사용할 때 목 전체가 불편함을 느낀다.

$\begin{array}{lllll}0 & 1 & 2 & 3 & 4 \\ 0 & 1 & 2 & 3 & 4 \\ 0 & 1 & 2 & 3 & 4 \\ 0 & 1 & 2 & 3 & 4 \\ 0 & 1 & 2 & 3 & 4\end{array}$

Part III: 휴식 후 음성향상

17. 쉬고 난 뒤에는 목소리가 좋아진다.

$\begin{array}{lllll}0 & 1 & 2 & 3 & 4\end{array}$

18. 쉬고 난 뒤에는 목소리를 낼 때 힘이 덜 든다.

$\begin{array}{lllll}0 & 1 & 2 & 3 & 4\end{array}$

19. 쉬고 난 뒤에는 목소리의 거친 정도가 줄어든다. 